\title{
EDUCAÇÃO E TRABALHO: A EDUCAÇÃO GARANTE VIDA EMANCIPADA DENTRO DO TRABALHO?
}

\author{
Fernanda Maria Fornaziéri MUSTO ${ }^{1}$ \\ Luci Regina MUZZETI ${ }^{2}$
}

RESUMO: Este trabalho visa buscar respostas e levantar reflexões sobre o questionamento se a convergência entre trabalho e educação é possível a partir de um propósito de vida emancipada e crítica, em que o trabalho possa ser realizado ao mesmo tempo em que as condições para que a reflexão crítica possa acontecer e que os cidadãos passem a compreender e interferir nos processos de produção. Apresentamos algumas referências de pensadores e estudiosos em como a educação e o trabalho se relacionam e buscamos dentre as alternativas educacionais que mencionam a preparação para o trabalho características que permitam concluir se ambos os propósitos podem coexistir no ambiente educacional. Identificamos uma programação que visa preparação para o trabalho e analisamos o programa e a metodologia para verificar sobre a efetividade de se preparar o aluno para algo mais do que seu propósito de servir ao trabalho de forma adequada. Além da análise de programa foram assistidas três aulas de três horas cada. Os resultados encontrados indicam uma convergência de propósitos mesmo que antagônicos, mas levantam um questionamento em relação à formação docente necessária para tal atividade ter sucesso.

PALAVRAS-CHAVE: Educação para o trabalho. Emancipação. Formação.

\section{Introdução}

Este trabalho visa buscar respostas e levantar reflexões sobre o questionamento se a convergência entre trabalho e educação é possível a partir de um propósito de vida emancipada e crítica, em que o trabalho possa ser realizado ao mesmo tempo em que as condições para que a reflexão crítica possa acontecer e que os cidadãos passem a compreender e interferir nos processos de produção. Abordamos levemente o sistema econômico em que estamos inseridos e buscamos dentre as alternativas educacionais que mencionam a preparação para o trabalho características que permitam concluir se ambos os propósitos podem coexistir no ambiente educacional. Para tanto refletimos inicialmente sobre o trabalho e o processo educacional, dentro da visão de alguns pensadores e estudiosos, e após buscamos dentro de uma programação que visa preparação para o trabalho o programa e a

\footnotetext{
${ }^{1}$ Doutoranda em Educação Escolar. Unesp - Universidade Estadual Paulista. Faculdade de Ciências e Letras Pós-Graduação em Educação Escolar. Araraquara - SP - Brasil. 14800-901.

${ }^{2}$ UNESP - Universidade Estadual Paulista. Faculdade de Ciências e Letras - Departamento de Didática. Araraquara - SP - Brasil. 14800-901 - lucirm@fclar.unesp.br
} 
metodologia para analisarmos sobre a efetividade de se preparar o aluno para algo mais do que seu propósito de servir ao trabalho de forma adequada.

\section{Referencial Teórico}

Trouxemos a contribuição de vários pesquisadores, embora iremos nos ater mais fortemente ao referencial teórico tal qual formulado por Pierre Bourdieu nas noções de habitus e capital cultual, social e econômico.

Para iniciarmos em uma reflexão acerca do trabalho nos valemos da contribuição teórica de Marx (1983, p.149-150, grifo nosso) para iniciar uma breve discussão, tomando por base seu capítulo quarto de O Capital:

Antes de tudo, o trabalho é um processo entre o homem e a Natureza, um processo em que o homem, por sua própria ação, media, regula e controla seu metabolismo com a Natureza. Ele mesmo se defronta com a matéria natural como uma força natural. Ele põe em movimento as forças naturais pertencentes à sua corporalidade, braços e pernas, cabeça e mão, a fim de apropriar-se da matéria natural numa forma útil para sua própria vida. Ao atuar, por meio desse movimento, sobre a Natureza externa a ele e ao modificá-la, ele modifica, ao mesmo tempo, sua própria natureza. Ele desenvolve as potências nela adormecidas e sujeita o jogo de suas forças a seu próprio domínio. [...] No fim do processo de trabalho obtém-se um resultado que já no início deste existiu na imaginação do trabalhador, e portanto idealmente. Ele não apenas efetua uma transformação da forma da matéria natural; realiza, ao mesmo tempo, na matéria natural seu objetivo, que ele sabe que determina, como lei, a espécie e o modo de sua atividade e ao qual tem de subordinar sua vontade. E essa subordinação não é um ato isolado. Além do esforço dos órgãos que trabalham, é exigida a vontade orientada a um fim, que se manifesta como atenção durante todo o tempo de trabalho, e isso tanto mais quanto menos esse trabalho, pelo próprio conteúdo e pela espécie e modo de sua execução, atrai o trabalhador, portanto, quanto menos ele o aproveita, como jogo de suas próprias forças físicas e espirituais. Os elementos simples do processo de trabalho são a atividade orientada a um fim ou o trabalho mesmo, seu objeto e seus meios.

Trazendo ainda outra forma de expor a questão do trabalho na sociedade, Dereymez (1995) aponta que o trabalho é atividade central para garantir a sobrevivência de homens e mulheres:

O trabalho constitui uma das bases fundadoras da economia de qualquer sociedade, uma força social de produção de bens e serviços e uma fonte de renda e sobrevivência de grandes segmentos das populações humanas. Além de ser uma fonte de income, constitui também um instrumento de inserção social. 
E Dereymez(1995) ainda sublinha que “[...] o trabalho determina as relações entre os diferentes grupos, classes e setores da sociedade, mediante os quais se definem parâmetros de identidade social e cultural.”

Além e como conseqüência disso, a forma como o trabalho se organiza na sociedade influi diretamente na forma como o sistema educacional também é organizado:

\begin{abstract}
Na verdade, todo sistema educacional se estrutura a partir da questão do trabalho, pois o trabalho é a base da existência humana, e os homens se caracterizam como tais na medida em que produzem sua própria existência, a partir de suas necessidades. Trabalhar é agir sobre a natureza, agir sobre a realidade, transformando-a em função dos objetivos, das necessidades humanas. A sociedade se estrutura em função da maneira pela qual se organiza o processo de produção da existência humana, o processo de trabalho. (SAVIANI, 1986, p.14).
\end{abstract}

Além dessa faceta, Ramos (2001) nos aponta que o processo educacional visa “[...] promover a possibilidade de o homem desenvolver-se e apropriar-se do seu ser de forma global, de todos os seus sentidos e potencialidades como fonte de gozo e de realização.”

Entendemos, portanto, que a educação preparará para o trabalho, mas deve cumprir uma finalidade ainda mais ampla, de desenvolvimento de potencialidades e de "apropriação de si mesmo.”

Em assim sendo, a educação assume um papel contraditório, pois reafirma o homem como ser social a partir do trabalho, preparando-o para este, mas, até na observância de que o processo educacional precisa desenvolver a plena potencialidade do homem, cria as condições para que o sistema laboral seja questionado e criticado.

Considerando que antes da Revolução Industrial a educação se pautava por fornecer a bem poucos o privilégio do estudo, a educação de caráter geral, clássico e científico, com a modificação do processo econômico, há nas formas de se entender educação uma alteração significativa. O projeto de educação presente ao final do século XVIII se pauta pela concepção de educação para as massas como fator de racionalização da vida produtiva e econômica. A necessidade do capital em reproduzir a força de trabalho como mercadoria, para suprir as linhas de produção, modificou o entendimento da noção de educação ao mesmo tempo em que iniciou a massificação do acesso ao processo educacional e a proliferação de escolas. 
Esse processo não ocorreu de forma linear e sem contradições. Ao invés, a educação preparava os súditos para serem cidadãos livres, mas ao mesmo tempo precisavam estar prontos para a necessidade de reposição de mão-de-obra.

Ao longo do tempo e com o avanço das relações capitalistas de produção, a tendência de universalização de técnicas básicas entre indústrias de ramos diferentes gerou a necessidade de aprendizado de conhecimentos e desenvolvimento de destrezas que poderiam ser úteis a vários tipos de trabalho. Assim, a aprendizagem para o trabalho passou a acontecer também nas escolas, que começaram a assumir o papel não só de socialização, mas de transmissão do saber técnico.

As profissões modernas são definidas pela divisão social do trabalho, e os saberes relacionados a cada uma destas, se tornam objetos de estudo na formação profissional do indivíduo no processo de escolarização. Há, evidentemente, uma distinção clara de acordo com o nível de complexidade e de escolaridade exigidas, hierarquizadas em consonância com as classes sociais a que se destinam.

Além destas questões, trazemos o arcabouço teórico de Pierre Bourdieu acerca das questões sociais, econômicas e culturais influenciando o indivíduo na apreensão de certos conhecimentos e na facilidade ou não de incorporação de atitudes mais ou menos valorizadas simbolicamente seja no ambiente do trabalho mais particularmente ou na vida em sociedade, mais amplamente.

Todas as condições existentes no seio familiar ou em sua primeira infância tendem a deixar marcas invisíveis nos indivíduos, em que posicionamentos quase imperceptíveis podem definir a forma de uma pessoa se utilizar ou não de determinada atitude ou de interiorizar determinado valor.

O capital econômico age promovendo acessos a instrumentos culturais que desenvolvem mais precocemente em uns do que em outros o aprendizado de certos valores simbólicos altamente valorizados quanto mais se deseja ascender na escala social. Além disso, proporciona um meio mais rico em nutrientes intelectuais para que o indivíduo possa iniciar seu processo de reflexão com autonomia e confiança.

A característica demográfica da família também influencia o grau de atenção e também valores monetários a serem investidos em cada criança, e assim permitir um desenvolvimento mais ou menos lento.

O capital cultural tal como explicado por Bourdieu, é o sistema de valores implícitos que é passado aos filhos de forma mais indireta que direta, e que tende a definir as atitudes frente à instituição escolar. Muito mais do que apenas os pais, mas todos os valores que 
permeiam o grupo familiar, como o nível cultural dos ascendentes de um e outro ramo da família, além das pessoas que convivem com a criança, contribuem para a definição de como será o processo de aculturação dessa criança. Isso pode definir a aversão ou simpatia inicial pelos professores, o gosto pela leitura, a vontade de descobrir mais do que é apresentado.

Também contribui fortemente para a facilidade lingüística, altamente valorizada nos meios acadêmicos, e que abre portas das instituições reservadas antigamente apenas aos filhos da elite, local onde se teoricamente se promoveria mais amplamente o estímulo à reflexão crítica.

\section{Objetivos}

Analisando um dos programas disponíveis que visa a preparação para o trabalho em uma instituição de ensino profissionalizante, buscamos elementos que possam indicar a presença de estímulo à reflexão crítica, bem como identificamos os conteúdos que são trabalhados com os jovens de classes sociais mais baixas.

\section{Metodologia}

Após o levantamento de aspectos importantes acerca da relação entre educação e trabalho historicamente, fizemos o levantamento a partir de informações solicitadas diretamente à instituição escolar profissionalizante participante dessa pesquisa, bem como analisamos três aulas destinadas aos alunos desse curso.

\section{Desenvolvimento}

O programa analisado que visa preparação para o mercado de trabalho para jovens de classes sociais mais baixas traz a seguinte descrição de objetivos e grade de programação.

O participante adquire conhecimentos e tem contato com novas tecnologias, num ambiente educacional que favorece a busca do autoconhecimento e contribui para enfrentar o mundo do trabalho.O programa foca a participação social ativa, a atitude empreendedora e as conexões como possibilidade de inserção na sociedade e no mundo do trabalho:

- Desenvolvimento Humano

- Desenvolvimento Pessoal

- Comunicação

- Atitude Empreendedora

- Sistemas e Processos Organizacionais

- Excelência no Atendimento e Relacionamento com o Cliente 
- Atividade Cultural e Visitas orientadas: Vivência. (SENAC, 2009).

A análise do programa acima nos aponta em algumas questões mais amplas, como o desenvolvimento humano e pessoal, em que o participante é estimulado a refletir sobre sua própria condição e a perspectiva histórica em relação ao trabalho e ao que é esperado dos profissionais hoje nas empresas e dessas pessoas hoje na sociedade.

As três aulas (de três horas cada, total de 9 horas) assistidas apontam nessa mesma direção, ou seja, de fato o jovem recebe orientação suficiente para que possa desenvolver um raciocínio lógico sobre questões muito presentes na sociedade, bem como reflete sobre as condições para que sejam bem aceitos no mercado de trabalho.

Encontramos, desde a apresentação dos objetivos e no programa, a ênfase em dois aspectos que entendemos determinantes para verificarmos a consonância efetiva entre necessidade do mercado de trabalho e educação, presente nessa instituição de ensino:

A atitude empreendedora, tão em voga nesse início de século, também aqui é apresentada, e busca desenvolver o senso de autonomia, confiança e desenvolvimento de ideias e projetos que possam culminar em uma atitude pró-ativa na empresa e na sociedade. Não necessariamente o estímulo à abertura de sua própria empresa é trabalhado, mas também a iniciativa em resolver problemas por conta própria, inovar no ambiente em que está inserido, acreditar na possibilidade de suas ideias. Se por um lado isso serve maravilhosamente bem às empresas, já que prepara os profissionais para identificarem e resolverem pontos de estrangulamento dentro da empresa e para utilizarem suas ideias para favorecerem a conquista de novos mercados ou o incremento na atuação junto ao mercado com o qual trabalham, por outro lado essa atitude vem a ser definidora para a vida do participante quanto à possibilidade de ele desenvolver projetos para a sua própria vida baseado nos seus gostos e interesses.

Estes, por sua vez, são identificados no tópico de auto-conhecimento, que é trabalhado permeando os outros conhecimentos, mas que busca propor ao jovem que analise suas atitudes, vontades, interesses, modos de ver sua vida e projeções para o futuro do que acham interessante.

Observamos que o aspecto Comunicação é trabalhado com ênfase. Há o destaque de que, com uma comunicação inadequada ou deficiente, toda inserção na sociedade fica prejudicada, sendo que as empresas percebem essas deficiências desde o currículo até a entrevista final, se chegar a acontecer. No caso de conseguirem o emprego, a possibilidade ou não de interagirem com outros membros da equipe e com os clientes a serem atendidos também abre ou fecha as portas profissionais destes alunos, o que fica destacado nas aulas. 
Os aspectos específicos do mundo do trabalho estão presentes em quase todos os momentos, sendo muito enfatizada a necessidade de preparação e inserção, para que o ser possa desenvolver plenamente seus potenciais, além de conseguir recursos para que tenha chance de eventualmente mudar de área se for essa sua vontade. Da forma como vivem hoje, os jovens dessas classes atendidas não têm tido a oportunidade de alterarem seu contexto se não por meio da inserção na vida profissional e conseqüente geração de renda.

Destacamos ainda as chamadas Competências Gerais do Programa:

- Refletir sobre sua identidade pessoal, social, profissional e política, identificando autonomamente as competências que percebe como necessárias para sua inserção no mundo do trabalho.

-Conviver e relacionar-se por meio do diálogo, organizando autonomamente o pensamento, construindo opiniões críticas, adquirindo confiança para expressar seu ponto de vista considerando as diferenças.

-Desenvolver a sensação de pertença, baseada no conhecimento e na apropriação dos seus direitos e deveres como cidadão a fim de agir de modo consciente na coletividade.

-Posicionar-se de maneira ética, cidadã e ecológica em todas as instâncias e em todos os relacionamentos - sociais, familiares, profissionais e comunitários.

-Identificar a dimensão coletiva dos acontecimentos, agindo politicamente para entender problemas, refletir sobre eles a fim de encontrar maneiras diferentes e criativas de resolvê-los e propor soluções.

-Identificar oportunidades, assumindo atitude empreendedora em sua relação com o mundo do trabalho e nos diferentes contextos - família, escola e Comunidade - em que possa contribuir e atuar.

-Reconhecer as redes de relações sociais, compreendendo sua importância para a organização e para o funcionamento do mundo atual, ampliando assim suas possibilidades de inserção.

A partir deste ponto destacamos outra questão que nos parece bastante pertinente: o reconhecimento das redes de relações sociais, que os coloca em contato com pessoas que dirigem instituições não governamentais, representantes de empresários, do poder público, de instituições educacionais. Isso enriquece sobremaneira seu capital social, possibilitando um contato com estruturas dinâmicas da sociedade que permitem compreender como as questões da sociedade podem ser alteradas mediante participação ativa. Isso para os alunos constitui em algo bastante diferente, uma vez que praticamente não têm coletividades nas quais participem além da escola e família. 
Nas aulas isso esteve presente no momento de agendamento de reunião conjunta com a Rede Social mediada pela instituição educacional, onde aproximadamente 120 instituições foram chamadas para a referida reunião. Nestas reuniões são escolhidos os espaços e situações da cidade que necessitam prioritariamente de iniciativas de desenvolvimento local, e as instituições parceiras se revezam nas ações para que melhorias possam ser feitas. Isso faz com que os alunos entrem em contato com as formas de mobilização da sociedade para resolução de problemas que são, em última análise, de todos os moradores de uma comunidade. Permite que reflitam sobre a possibilidade de alteração de uma realidade existente para uma outra mais desejável e projetada pelos cidadãos que utilizam ativamente seus conhecimentos e capacidades intelectuais para imaginarem e criarem uma sociedade mais próxima da desejada.

\section{Conclusões}

$\mathrm{Na}$ alternativa educacional preparatória para o trabalho analisada, concluímos que existe uma busca de desenvolvimento dos alunos que vai para mais distante do que apenas a preparação para uma posição profissional em uma empresa. Entretanto, notamos que mesmo essa característica é tida como necessária para que um profissional se torne mais efetivo dentro de seu ambiente de trabalho. O desenvolvimento de aspectos cognitivos precisa, nessas instituições, andar junto com o refletir sobre sua prática profissional. A informação sobre a dinamicidade do mundo do trabalho e a necessidade de atualização constante para que os conhecimentos não se tornem obsoletos e a presença destes jovens na empresa desnecessária, são trabalhados incessantemente.

Uma conclusão possível é a de que mesmo os professores não refletem demasiadamente sobre a situação do trabalho, mas buscam com afinco se prepararem para que seus alunos desta programação estudada tenham alternativas de desenvolvimento para além do seu contexto presente. A educação preparatória para o trabalho, neste caso, abre janelas para que a análise crítica e a reflexão que possibilita a emancipação aconteçam e se desenvolvam, mas esbarram na própria preparação e desenvolvimento dos docentes que atuam nessas programações.

Portanto, tão importante quanto a análise do proposto, é a de que os professores envolvidos possam de fato terem, eles mesmos, a análise crítica e a autonomia de pensamento necessárias para que possam estimular seus alunos e concretizarem o objetivo a que se 
propõem. É mister observar que tenham o arcabouço de conhecimento teórico necessário para que observem com clareza outras facetas das situações e da realidade.

\section{WORK AND EDUCATION: DOES EDUCATION GUARANTEE AUTONOMOUS LIFE IN WORK?}

ABSTRACT: This work intends to find answers and bring reflections about the question: is the convergence between work and education possible from a point of view of an autonomous and critical life, in which work can be done meanwhile the conditions for a critical reflection can happen and the citizens may comprehend and interfere in the production processes. We present some references from thinkers how work and education relate and we sought among the educational alternatives which mention the preparation for work characteristics that permit to conclude if both the purposes can coexist in the educational environment. We identified a course whose objective is the preparation for work and the program and methodology were studied to verify about the effectiveness from an adequate preparation of the student for something more than work. Besides, three classes of three hours each were attended. The results bring a questioning about the necessary teacher's formation for such an activity to achieve success.

KEYWORDS: Work. Education. Autonomous life. Pierre Bourdieu.

\section{REFERÊNCIAS}

DEREYMEZ, J. W. Le travail-histoire, perspectives. Grenoble: Presses Universitaires de Grenoble, 1995.

MARX, K. O capital. São Paulo : Abril Cultural, 1983. v.1, t.1.

RAMOS, M. A pedagogia das competências: autonomia ou adaptação? São Paulo: Cortez, 2001.

SAVIANI, D. O nó do ensino de $2^{\circ}$ grau. São Paulo: MEC;INEP;Cenafor, 1986. (Bimestre, n.1).

SENAC. Serviço Nacional de aprendizagem comercial. SENAC Araraquara. Programa educação para o trabalho: novas conexões. Disponível em:

$<$ http://www.sp.senac.br/jsp/default.jsp?newsID=DYNAMIC,oracle.br.dataservers.CourseDat aServer,selectCourse2\&course=4090\&template=395.dwt\&unit=ARA\&testeira=351 $>$. Acesso em: 23 fev. 2009.

\section{BIBLIOGRAFIA CONSULTADA}


BOURDIEU, P. A sociologia de Pierre Bourdieu. Organizado por Renato Ortiz. São Paulo: Olho d'Água, 2003.

Escritos de educação. Petrópolis: Vozes, 1998.

Coisas ditas. São Paulo: Brasiliense, 1990.

A economia das trocas simbólicas. São Paulo: Perspectiva, 1987.

Sociologia. São Paulo: Ática, 1983.

NOGUEIRA, M.; NOGUEIRA, C. Bourdieu e a educação. Belo Horizonte: Autêntica, 2004. 